\title{
EL DESARROLLO DE LA TEORÍA SOCIAL Y SUS CONTRIBUCIONES AL FENOMENO DE \\ LA PUNICIÓN
}

\author{
Norberto Hernández Jiménez*
}

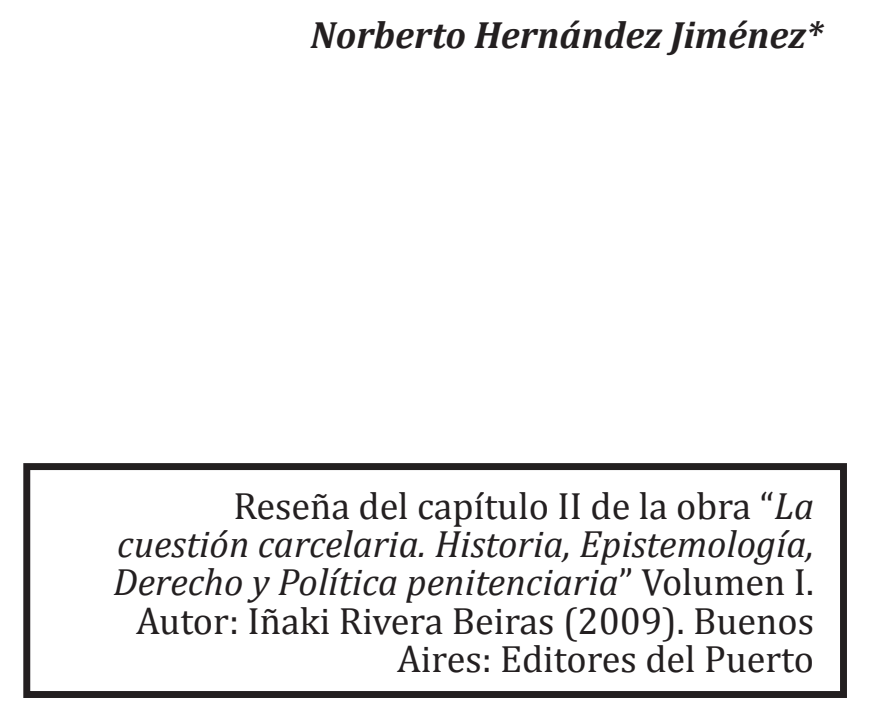

RESEÑA

\section{PALABRAS PRELIMINARES}

El texto gira en torno a la legitimación de la pena, recurriendo al pensamiento de los grandes filósofos del derecho penal, para quienes en el comienzo, la misma era entendida como una retribuciónreparación del mal causado con el delito ${ }^{1}$ y luego revistió una funcionalidad - bajo criterios utilitaristas ${ }^{2}$ - respecto al delincuente y la sociedad, observando igualmente el nacimiento de teorías intermedias, falseando en definitiva el axioma simplificado de la pena como consecuencia del delito.

A continuación se procede a diagramar algunas especificidades en los distintos períodos evolutivos de la pena.

\footnotetext{
* Abogado, especialista y magister en derecho penal de la Universidad Libre. Especialista en derecho constitucional y en derecho administrativo de la Universidad del Rosario. Candidato a doctor en Derecho de la Universidad de los Andes. Coordinador del Grupo de Prisiones de la misma Universidad y Conjuez del Tribunal Superior de Florencia (Caquetá) - Sala Penal -.

1. En este sentido Ferrajoli, Kanty Hegel

2. En este sentido Mir Puig, Hassemery Roxin
} 
RESEÑA: El desarrollo de la teoría social y sus contribuciones al fenómeno de la punición

ILUSTRACIÓN $\left\{\begin{array}{l}\text { ORIGEN: Segunda mitad del siglo XVI } \\ \text { CONTEXTO: Prácticas de profilaxis social por enfermedades } \\ \text { RESPUESTA: Panoptismo } \\ \text { CONSECUENCIA: Secuestro del mercado de trabajo a quienes mostrarán } \\ \text { rebeldía a las nuevas reglas de juego } \\ \text { FUNCIÓN DE LA PENA: Retribución }\end{array}\right.$
ORIGEN: Finales del siglo XIX y principios del XX
RESPUESTA: Aplicación de las leyes de la naturaleza a las ciencias sociales CONSECUENCIA: -Adopción de la ley de causalidad como instrumento descriptivo-explicativo de todos los fenómenos
-Búsqueda de una explicación científica de la criminalidad
Sistema penitenciario progresivo
POSITIVISMO $^{6}$ FUNCIÓN DE LA PENA:
-Readaptación
-Resocialización (Tratamiento médico, psiquiátrico y psicológico)
-Prevención

ORIGEN: 1870

ANARQUISMO $\left\{\begin{array}{l}\text { CONTEXTO: Socialismo } \\ \text { ANARQUISMO RESPUESTA: -Repudio general contra el castigo }\end{array}\right.$

-El crimen contiene en sí la pena

CONSECUENCIA: Fuertemente criticado por el positivismo

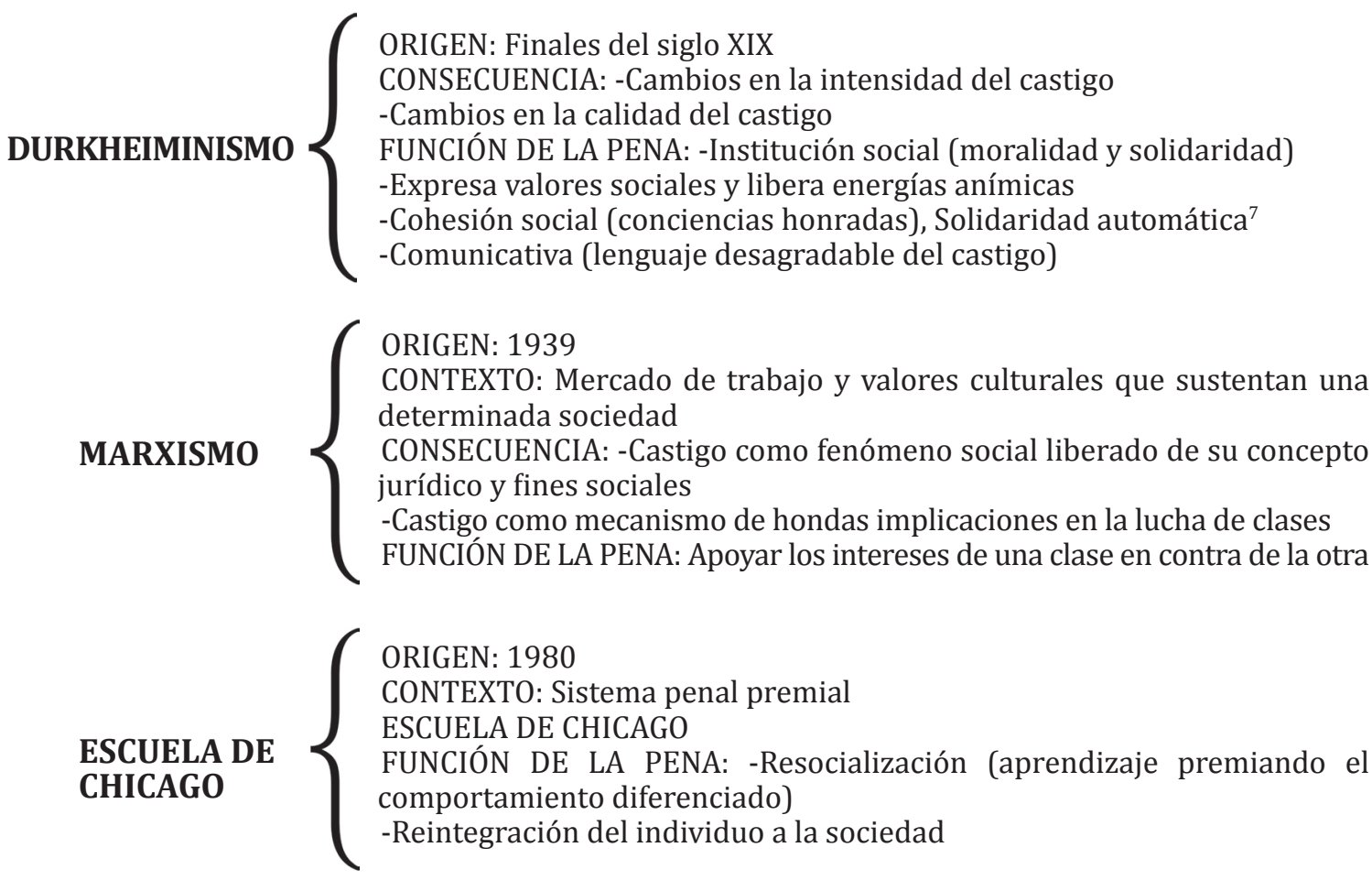


Ahora bien, respecto al funcionalismo se hace referencia a que la función de la pena allí contenida, atiende a criterios de prevención general positiva o prevención- integración ${ }^{8}$.

En cuanto a la visión de Foucault se destaca su visión en procura de la transformación del individuo recluido en establecimiento carcelario, a pesar de sus comentarios críticos basados en la falta de efectividad de dicha limitación del derecho de locomoción, básicamente instituida por criterios culturales.

El discurso weberiano comienza con la referencia de la administración de justicia como mecanismo expiatorio entre los clanes lo que acorde con criterios de seguridad jurídica desarrollados bajo la lupa económica, fueron superados, burocratizando el proceso penal, exaltando esto último en la medida que el manejo del sistema se encuentra encomendado a personal capacitado, racionalizando así el castigo.

Respecto al tratamiento psiquiátrico y psicológico, el profesor Rivera Beiras acude a los estudios de Goffman que denotan gran cercanía con el pensamiento de Bentham sobre los establecimientos panópticos, pero que en definitiva reprocha bajo el rotulo de adaptacióndesintegración, con base en los distintos sufrimientos que debe padecer el penado, desde su internamiento en el centro carcelario o en la respectiva institución médica, concluyendo que las instituciones totales no persiguen verdaderamente una visión cultural.

Finalmente, el autor trae a colación el pensamiento de Garland quien cataloga al castigo como artefacto cultural que debe ir indefectiblemente acompañado de las sensibilidades sociales y aun cuando no utiliza el término de prevención general, si cataloga la pena como instrumento de comunicación de significados a la sociedad, con el plus que este mensaje no se limita al delito, sino a todas las relaciones que se desprenden de la agrupación social, propugnado por la separación teleológica de la pena con la perspectiva jurídica.
3. En este sentido Jakobs, Pérez Manzano y Luhman

4. Término acuñado por Foucault en relación con la lucha contra el contagio de la lepra

5. Siguiendo las doctrinas kantiana y hegeliana

6. Contando como principales exponentes (fundadores) a Lombroso, Garofalo y Ferri y más adelante Von Liszt

7. Término acuñado por Durkheim

8. Pregonada por Jakobs 
